\title{
CIVIL FLIGHT GUIDE WHEN TAKE OFF FROM THE GADING FIELD
}

\author{
Maria Ermelinda Bupu \\ Jurusan Teknik Dirgantara-Sekolah Tinggi Teknologi Adisutjipto \\ mariaermelindabupurau95@gmail.com
}

\begin{abstract}
Until now, Gading Airfield cannot be used for commercial flights. However, in the future, along with the increasing number of commercial and training flights, Gading Airfield will continue to be developed to help smooth flights in DI Yogyakarta. Thus some flight guidelines for civil aviation must be made. Several analysis and calculation methods are carried out starting from general analysis of the airfield, counting and design of the takeoff guide patron starting from two sides of the runway, namely from RWY 10 and 28. The calculation consists of MTOW calculation which is limited by PCN, calculation of takeoff path, calculation Takeoff distance requirement, calculation of climb segment up to 1.500 feet, calculation of flight turn 1.500 feet, to design patron takeoff path guidance.
\end{abstract}

Keyword: Flight Path, Procedure Turn

\section{Latar Belakang}

Lapangan terbang Gading dengan kode ICAO WAHG merupakan lapangan terbang milik Pemda DIY yang dikelola dan dimanfaatkan oleh Pemerintah daerah dalah hal ini Dinas Perhubungan DIY dan oleh Lanud Adisutjipto Yogyakarta. Lapangan terbang ini dibangun tanggal 6 Februari 2004 hingga saat ini digunakan sebagai lokasi latihan terbang bagi para calon penerbang TNI AU dan kegiatan-kegiatan pembinaan potensi kedirgantaraan oleh pemuda, mahasiswa, dan organisasi-organisasi hobi kedirgantaraan. Salah satu pesawat yang digunakan di lapangan terbang Gading saat ini adalah pesawat ultralight PK-S-160. Hingga saat ini lapangan terbang Gading belum bisa digunakan untuk penerbangan komersial. Tetapi di waktu yang akan datang seiring dengan semakin padatnya jumlah penerbangan baik komersial maupun latihan terbang, maka lapangan terbang Gading akan terus dikembangkan untuk membantu kelancaran penerbangan di Yogyakarta Saat lapangan terbang ini digunakan sebagai penerbangan komersial, dimungkinkan penerbangan akan dilakukan dari Gading karena dalam sistem multi airport tidak semua penerbangan bisa dibackup dengan penerbangan internasional karena setiap bandara mempunyai karakteristik masingmasing.Dengan demikian beberapa panduan terbang untuk penerbangan sipil haruslah dibuat. Panduan terbang tersebut terdiri dari panduan saat tinggal landas baik dari sisi arah RWY-10 dan RWY-28 dari lapangan terbang Gading (WAHG) menuju bandar udara terdekat atau aternatif yaitu bandar udara Adisutjipto (WAHH) dan Yogyakarta International Airport (WAHI), untuk selajutnya pesawat melanjutkan penerbangan ke rute-rute yang dituju sebagai destinasi misi terbang. Panduan terbang lain yang harus disiapkan adalah panduan pendaratan prosedur pendaratan. Panduan tinggal landas didasarkan pada kondisi dan rute bandar udara Gading terhadap bandar udara terdekat yaitu bandar udara Adisutjipto dan Yogyakarta International Airport [1]. Beberapa penelitian sebelumnya terkait dengan prosedur terbang telah dibahas oleh beberapa peneliti. Penelitian yang berjudul "Metoda Short Takeoff Landing (Studi Kasus Prestasi Terbang Takeoff-Landing Pesawat Udara Turbo Prop CN235)" [1]. Penelitiannya pada pesawat dengan kategori Short Take-Off Landing dengan berat take-off antara $9.072 \mathrm{~kg}$ hingga $22.680 \mathrm{~kg}$. Dengan kemampuan melewat rintangan setinggi $50 \mathrm{ft}$ untuk jarak take-off dan landing sejauh $1.500 \mathrm{ft}(450 \mathrm{~m})$.Pengembangan pesawat dengan kategori 
tersebut perlu memperhatikan tiga persyaratan umum yaitu kemampuan aerodinamika yang tinggi, tenaga mesin yang besar, dan teknik pilot yang baik yang disertai dengan kekuatan struktur yang mampu menahan beban berat. Pada CN235-100 (serial N-16) dengan menggunakan flap $23^{\circ}$, saat pengujian performance take-off di PT Dirgantara Indonesia pada tahun 1996. Pengujian tersebut juga termasuk uji rejected take-off atau accelerate stop distance dengan menggunakan flap $10^{\circ}$ pada tenaga penuh dimana kemudian salah satu mesin dimatikan untuk mencapai kondisi kritis dan pilot mengurangi daya propulsi mesin lainnya untuk dapat berhenti di ujung landasan.Sementara peneliti yang berjudul "Analisis Panjang Runway untuk Pendaratan dan Take-off Pesawat Airbus A330-200 dan A330- 300" [2]. Penelitiannya terkait dengan Bandara Radin Inten II merenovasi bandara mulai dari memperpanjang landasan pacu serta memperluas apron dan bangunan terminalnya. Landasan pacu diperpanjang dari sebelumnya $2.500 \mathrm{~m}$ menjadi 3.000 m.Pengembangan ini dilakukan karena Bandara Radin Inten II dipilih menjadi embarkasi haji penuh dan juga karena adanya potensi peningkatan aktivitas bandara setiap tahunnya. Bandara juga harus mampu mengakomodasi pesawat Airbus A330-200 dan A330-300 untuk meningkatkan kapasitas penumpang. Penelitian ini dilakukan dengan mengevaluasi kondisi yang ada dari Bandara Radin Inten II dan menganalisis apakah landasan pacu di Bandara Radin Inten II dapat mengakomodasi Airbus A330-200 dan A330300.Hasil analisis menunjukkan bahwa terdapat peningkatan yang signifikan dalam kegiatan penumpang dan kargo. Selanjutnya, Bandara Radin Inten II dapat melayani jenis pesawat Airbus A330-200 dengan panjang landasan pacu yang dibutuhkan $2.753 \mathrm{~m}$ untuk pesawat tersebut, sedangkan pesawat A330-300 tidak dapat dilayani karena pesawat ini membutuhkan panjang landasan $3100 \mathrm{~m}$ untuk lepas landas dan mendarat dengan aman.Penelitian yang berjudul "Waktu Tunggu Takeoff dan Landing Pesawat Udara Pada Runway Bandar Udara Soekarno Hatta" membahas tentang latar belakang permasalahan padatnya penerbangan di runway bandar udara ini tentunya akan menimbulkan antrean pelayanan air traffic control pada taxiway [3]. Apabila waktu tunggu dalam antrean cukup padat, tentunya akan menimbulkan kerugian dari penggunaan avtur, untuk mengetahui waktu tunggu rata-rata setiap pesawat udara saat peak hours di bandar udara Soekarno Hatta ini, maka perlu dilakukan penelitian terkait dengan hal tersebut diatas dengan menggunakan teori antrian pada taxiway Bandar udara Soekarno Hatta. Dengan nilai laju efektif 1 pesawat permenit, dan dengan pelayanan per pesawat 4 menit, maka setiap 1 pesawat terlayani, masih terdapat 4 pesawat menunggu dalam antrean. Sehingga, untuk pesawat ke 4 hams menunggu selama 16 menit untuk dapat takeoff dan landing.Skripsi yang berjudul "Perancangan Procedure Turn Untuk Take off Dan Landing Menggunakan Metode Procedure Turn Penerbangan Visual Flight Rules Pada Lapangan Terbang Gading" [4]. Pada skripsi tersebut Agung menganalisis tentang bagaimana dimensi landasan pacu bandar udara Gading-Gunung Kidul sebagai syarat pengoperasian penerbangan sipil sesuai dengan regulasi penerbangan sipil, melakukan pemetaan ketinggian permukaan daratan area operasi bandar udara Gading sebagai referensi batas MSA untuk penerbangan visual, serta melakukan perancangan prosedur take off dan prosedur pendaratan untuk penerbangan visual di lapangan terbang Gading Gunung Kidul.Dari hasil penelitian tersebut, ditarik kesimpulan penerbangan pada bandar udara atau lapangan terbang Gading Gunung Kidul dilakukan dengan prosedur VFR dengan batasan-batasan: (a) daylight, (b) jarak pandang tidak kurang dari $5 \mathrm{~km}$, (c) ketinggian terbang jelajah tidak lebih dari 10.000 feet, (d) cloud ceiling saat pesawat akan melakukan takeoff dan landing tidak lebih rendah dari 1.000 feet di atas obstacle tertinggi di area operasi bandara atau lapangan terbang.Kajian pustaka adalah suatu kegiatan penelitian yang bertujuan melakukan kajian secara sungguh-sungguh tentang teori-teori dan konsep-konsep yang berkaitan dengan topik yang akan diteliti sebagai dasar dalam melangkah pada tahap penelitian selanjutnya. Fungsi kajian pustaka adalah mengemukakan secara sistematis tentang hasil penelitian yang diperoleh terlebih dahulu dan hubungannya dengan penelitian yang dilakukan. Penelitian tugas akhir mengenai Analisis 
Lapangan Terbang Gading Saat Dioperasikan Bagi Penerbangan Sipil Dengan Melakukan Perancangan Panduan Tinggal Landas RWY-10 dan RWY-28. Sebagai pembanding dalam tugas akhir ini, sehingga memudahkan penulis untuk menarik kesimpulan dan memperlihatkan perbedaan mendasar dari perbedaan sebelumnya [5].

\section{Metodologi Penelitian}

Metode pengumpulan data merupakan prosedur sistematis yang diperlukan untuk memperoleh data. Metode pengumpulan data dalam skripsi ini peneliti menggunakan metode sebagai berikut:

a. Metode Wawancara (interview)

Merupakan suatu teknik penelitian dengan cara bertanya atau mewawancarai orang-orang yang berkompeten dalam penyusunan skripsi ini atau kepada pihak- pihak yang berhubungan dengan objek penelitian.

b. Metode Studi Pustaka

Data yang diperoleh dengan cara mempelajari bahan-bahan yang tertulis, data tersebut dapat berupa buku panduan, brosur, dokumen-dokumen serta bahan- bahan yang berkaitan dengan masalah yang sedang diteliti.

c. Metode Multimedia atau Internet

Data yang diperoleh dengan cara mencari sumber-sumber data melalui media internet.

Langkah-langkah yang perlu dilakukan dalam mengidentifikasi masalah yang berhubungan dengan pengembangan sisi udara dana alat bantu pendaratan di sebuah Bandar Udara, jenis penelitian ini adalah penelitian kasus atau studi kasus. Studi kasus adalah penelitian yang dilakukan untuk mendapatkan data langsung dari lapangan dan diikuti dengan penelitian deskriptif analisis, dimana analisis didasarkan pada data-data fisik yang terdapat di Lapangan Terbang Gading Gunung Kidul. Dari data-data yang sudah tersedia kemudian dilakukan penelaahan berdasarkan teori. Penelitian ini kemudian dianalisis prospek dan kendala yang mungkin dihadapi dalam pengembangan sisi udara dan alat bantu pendaratan di Lapangan Terbang Gading Gunung Kidul.Metode analisis menggambarkan tahapan yang akan dilalui untuk mendapatkan hasil yang akan dicapai dari data-data yang dievaluasi dengan rumus atau parameter tertentu

\section{Hasil dan Pembahasan}

Analisa yang dilakukan pada runway di lapangan terbang Gading terkait dengan panduan approach adalah analisis runway berupa design runway azimuth serta acuan pendaratan dengan menggunakan satu titik approach yang ditentukan pada titik tertentu sebelum titik holdingnya. Dalam analisis ini dirancang suatu titik tertentu sebagai titik holding pada posisi yang cukup untuk pesawat melakukan approach berjarak 10-15 NM sesuai dengan penghitungan performa terbang saat melakukan approah dan climb secara VFR serta penentuan titik saat pesawat mulai melakukan design approach. Analisis dimensi runway ini terdiri dari penghitungan TORA, ASDA, dan TODA. Penelitian dan pengamatan dilakukan pada seluruh permukaan dan panjang landasan dari RWY 10 hingga ujung RWY 28.Pengukuran panjang landasan dilakukan secara manual dengan menggunakan mistar gulung untuk menentukan berapa panjang dari ujung RWY 28 hingga ujung RWY 10 serta melakukan pengamatan pada bagian bagian runway yang perlu mendapatkan perhatian yaitu:

a. Pengukuran panjang landasan dari ujung RWY 10 hingga ujung RWY 28 didapatkan hasil nilai panjang sebesar 1.432 meter.

b. Terdapat retakan kecil pada permukaan runway, yaitu: 
1) 128 meter dari end beginning RWY 28 pada sisi kiri dengan panjang retakan sebesar 168,7 meter.

2) 216,4 meter intersection taxiway pada posisi center-line runway dengan luasan 8,3 meter x 11,8 meter atau seluas 97,94 meter $^{2}$.Berikut ini denah kondisi dan posisi retakan permukaan runway hasil observasi visual di runway

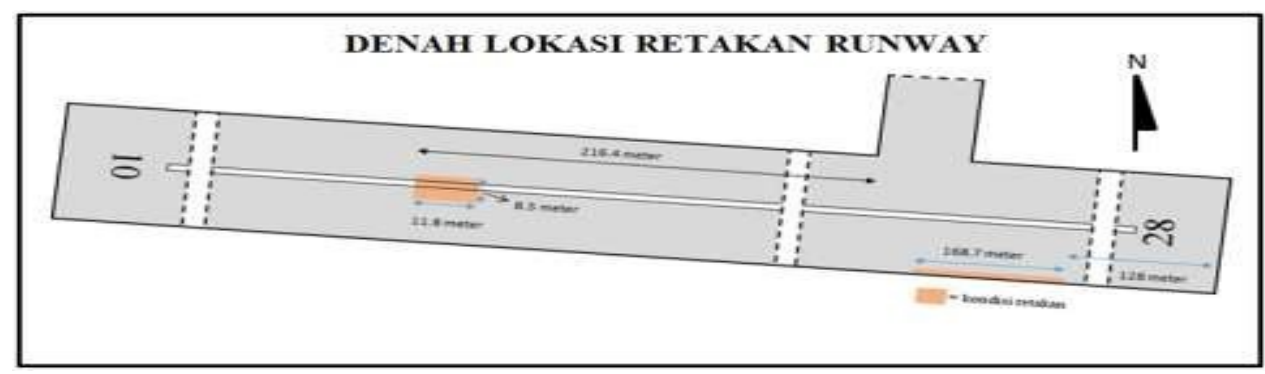

Gambar 1. Denah lokasi retakan pada runway

c. Penentuan Takeoff Run Available (TORA)

Penelitian dan pengamatan dilakukan pada seluruh permukaan dan panjang landasan dari RWY 10 hingga ujung RWY 28. Pengukuran panjang landasan dilakukan secara manual dengan menggunakan mistar gulung untuk menentukan berapa panjang dari ujung RWY 28 hingga ujung RWY 10 serta melakukan pengamatan pada bagian bagian runway yang perlu mendapatkan perhatian yaitu:

TORA RWY $10 \quad: 1.400$ meter

TORA RWY $28 \quad: 1.400$ meter

Berikut ini adalah gambar TORA:

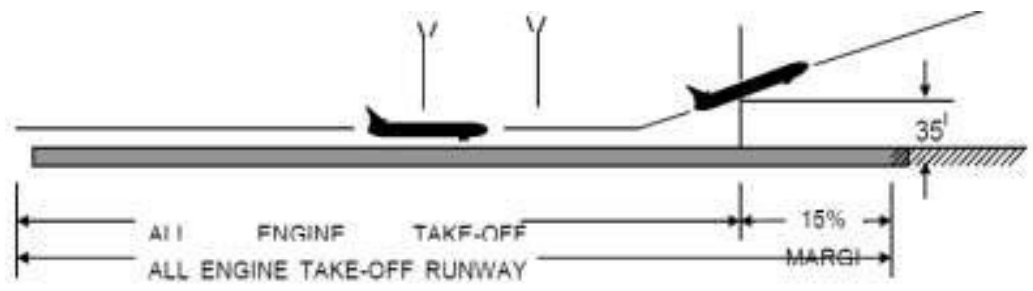

Gambar 2. TORA

(Sumber: Airlines Basic Operation Manual)

d. Penentuan Accelerate Stop Distance Available (ASDA)

Dari pengamatan di lapangan diketahui bahwa runway lapangan terbang tidak terdapat stopway baik di end of RWY 10 maupun end of RWY 28 sehingga nilai dari ASDA sebesar:

ASDA RWY $10=$ TORA + Stop way

ASDA RWY $10=1.400+0$

ASDA RWY $10=1.400$ meter ASDA

RWY $28=$ TORA + Stop way ASDA

RWY $28=1.400+0$

ASDA RWY $28=1.400$ meter 
Berikut ini adalah gambar ASDA:

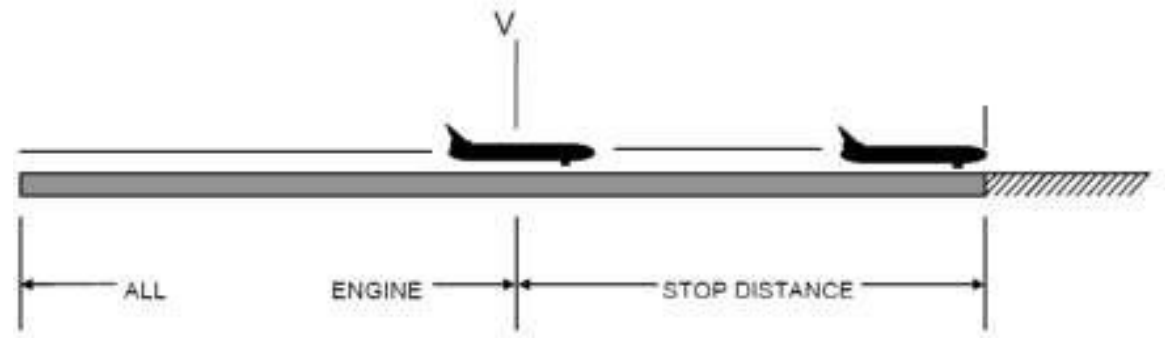

Gambar 2. ASDA

(Sumber: Airlines Basic Operation Manual)

e. Penentuan Takeoff Distance Available (TODA)

Dari hasil observasi di lapangan didapatkan data temuan obyek yang dimungkinkan menjadi obstacle. Obtek ditetapkan obstacle jika posisi dan ketinggian obyek menghasilkan slope yang melebihi batas $1,25 \%$. Obyek dalam pengamatan ini adalah sebagai berikut:

1) Obyek pada jalur tinggal landas arah RWY 28 terdiri dari:

a) Pohon akasia 1, jarak dari end of RWY 10 sejauh 102 meter setinggi 128 $\mathrm{cm}$.

b) Pohon akasia 2, jarak dari end of RWY 10 sejauh 120 meter setinggi 145 $\mathrm{cm}$.

c) Pagar, jarak dari end of RWY 10 sejauh 155 meter setinggi $170 \mathrm{~cm}$.

d) Rumah warga, jarak dari end of RWY 10 sejauh 450 meter setinggi $380 \mathrm{~cm}$.

2) Obyek pada jalur tinggal landas arah RWY 10 terdiri dari:

a) Tanaman semak 1, jarak dari end of RWY 28 sejauh 231 meter setinggi 175 $\mathrm{cm}$.

b) Pohon akasia 1, jarak dari end of RWY 28 sejauh 245 meter setinggi 197 $\mathrm{cm}$.

c) Tanaman semak 2, jarak dari end of RWY 28 sejauh 253 meter setinggi 126 $\mathrm{cm}$.

d) Pohon biduri, jarak dari end of RWY 28 sejauh 275 meter setinggi $138 \mathrm{~cm}$.

e) Pohon akasia 2, jarak dari end of RWY 28 sejauh 297 meter setinggi 210 $\mathrm{cm}$.

f) Pohon jati, jarak dari end of RWY 28 sejauh 365 meter setinggi $237 \mathrm{~cm}$.

Selanjutnya dilakukan penghitungan slope untuk masing masing obyek yang berpeluang menjadi obstacle dengan penghitungan sebagai berikut: Pada obyek di jalur tinggal landas arah RWY 28 berupa pohon akasia sejauh 102 meter setinggi $128 \mathrm{~cm}$.

$$
\begin{gathered}
\text { slope }=\frac{128 \mathrm{~cm}}{102 \text { meter }} \times 100 \% \\
\text { slope }=\frac{1,28 \text { meter }}{102 \text { meter }} \times 100 \% \\
\text { slope }=1,254901961 \%
\end{gathered}
$$

Dari data diatas dapat digambar panduan keberangkatan dengan posisi pesawat takeoff dari RWY-28 sebagai berikut: 


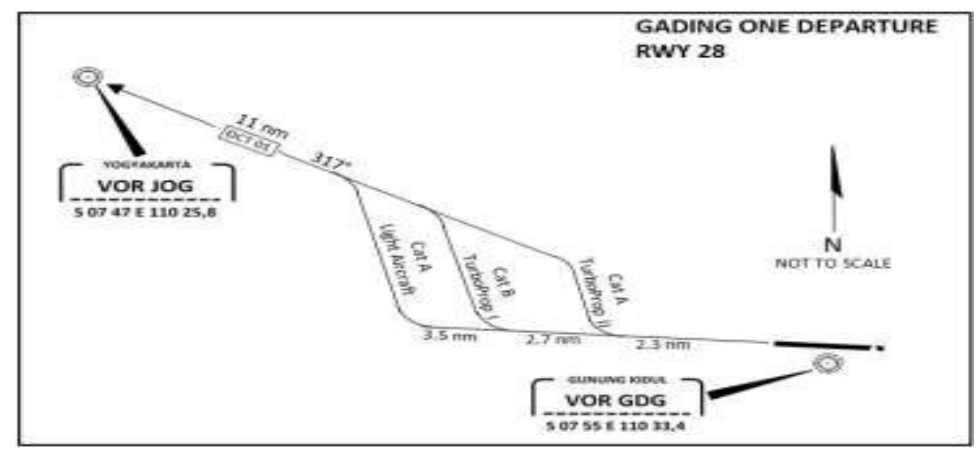

Gambar 3. Gading One Departure

Keterangan panduan:

- Pesawat Cat A light Aircraft, pesawat takeoff heading 280 Mag hingga climb ke ketinggian 1500 feet mencapai 3,5 nm selanjutnya berbelok ke kanan (right turn) bergabung dengan rute Direct One (Joining Delta Charlie Tango Zero One).

- Pesawat Cat A Turboprop II, pesawat takeoff heading 280 Mag hingga climb ke ketinggian 1500 feet mencapai 2,3 nm selanjutnya berbelok ke kanan (right turn) bergabung dengan rute Direct One (Joining Delta Charlie Tango Zero One).

- Pesawat Cat B Turboprop I, pesawat takeoff heading 280 Mag hingga climb ke ketinggian 1500 feet mencapai 2,7 nm selanjutnya berbelok ke kanan (right turn) bergabung dengan rute Direct One (Joining Delta Charlie Tango Zero One).

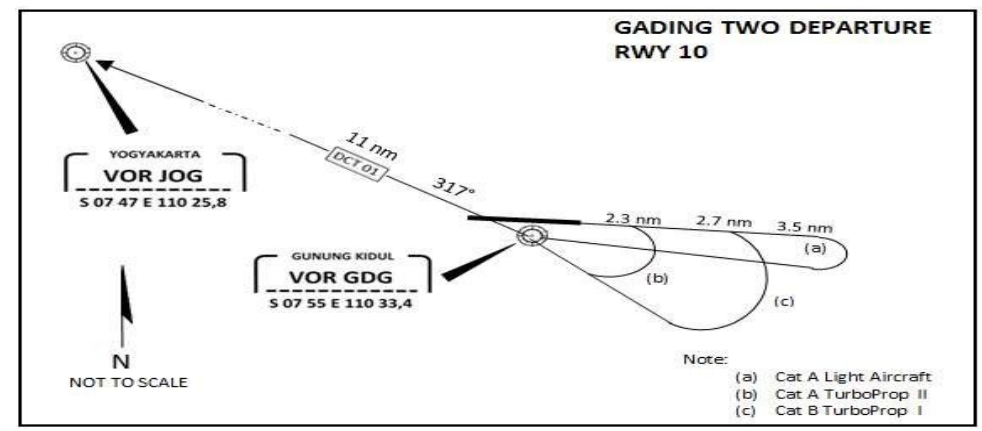

Gambar 4. Gading Two Departure RW=10

Keterangan panduan:

- Pesawat Cat A light Aircraft, pesawat takeoff heading 100 Mag hingga climb ke ketinggian 1500 feet mencapai 3,5 nm selanjutnya berputar balik (right turn back track) dan bergabung dengan rute Direct One (Joining Delta Charlie Tango Zero One).

- Pesawat Cat A Turboprop II , pesawat takeoff heading 100 Mag hingga climb ke ketinggian 1500 feet mencapai 2,3 nm selanjutnya berputar balik (right turn back track) dan bergabung dengan rute Direct One (Joining Delta Charlie Tango Zero One).

- Pesawat Cat B Turboprop I , pesawat takeoff heading 100 Mag hingga climb ke ketinggian 1500 feet mencapai 2,7 nm selanjutnya berputar balik (right turn back track) dan bergabung dengan rute Direct One (Joining Delta Charlie Tango Zero One). Dari data diatas dapat digambar panduan keberangkatan dengan posisi pesawat takeoff dari RWY-28 sebagai berikut: 


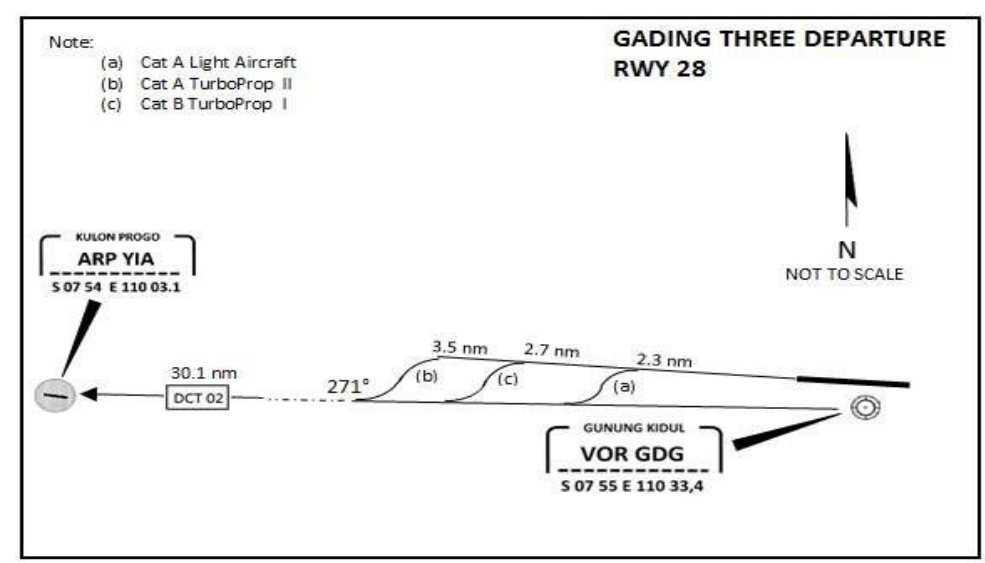

Gambar 5. Gading Three Departure RW-28

Keterangan panduan:

- Pesawat Cat A light Aircraft, pesawat takeoff heading 280 Mag hingga climb ke ketinggian 1500 feet mencapai 3,5 nm selanjutnya berbelok ke kiri (leftt turn) bergabung dengan rute Direct Two (Joining Delta Charlie Tango Zero Two).

- Pesawat Cat A Turboprop II , pesawat takeoff heading 280 Mag hingga climb ke ketinggian 1500 feet mencapai 2,3 nm selanjutnya berbelok ke kiri (leftt turn) bergabung dengan rute Direct Two (Joining Delta Charlie Tango Zero Two).

- Pesawat Cat B Turboprop I , pesawat takeoff heading 280 Mag hingga climb ke ketinggian 1500 feet mencapai 2,7 nm selanjutnya berbelok ke kiri (leftt turn) bergabung dengan rute Direct Two (Joining Delta Charlie Tango Zero Two).

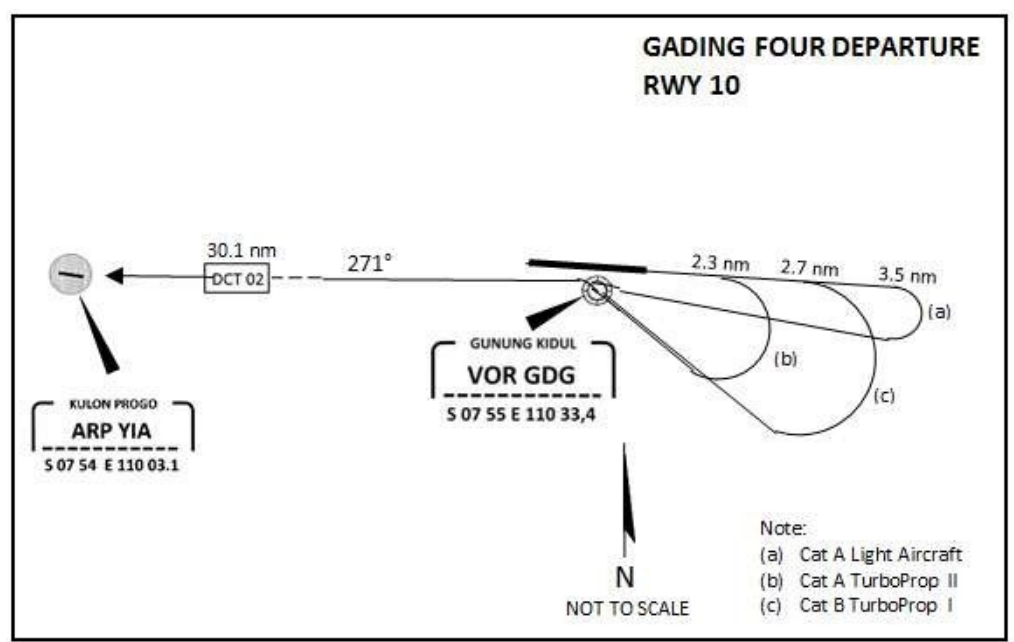

Gambar 6. Gading Four Departure RW-10

Keterangan panduan:

- Pesawat Cat A light Aircraft, pesawat takeoff heading 100 Mag hingga climb ke ketinggian 1500 feet mencapai 3,5 nm selanjutnya berputar balik (right turn back track) dan bergabung dengan rute Direct Two (Joining Delta Charlie Tango Zero Two).

- Pesawat Cat A Turboprop II , pesawat takeoff heading 100 Mag hingga climb ke ketinggian 1500 feet mencapai 2,3 nm selanjutnyaberputar balik (right turn back track) dan bergabung dengan rute Direct Two (Joining Delta Charlie Tango Zero Two). Pesawat Cat B Turboprop I, pesawat takeoff heading 100 Mag hingga climb 
ke ketinggian 1500 feet mencapai 2,7 nm selanjutnya berputar balik (right turn back track) dan bergabung dengan rute Direct Two (Joining Delta Charlie Tango Zero Two).

\section{Kesimpulan}

Dari analisis dan penghitungan didapatkan hasil bahwa runway Gading Airfield secara umum masih bisa digunakan dengan kekuatan MTOW sebesar21.530 kg (ATR 72 Basic Tire). Prosedur rute keluar dari Gading Airfield menuju JOG (WAHH) adalah $317^{\circ}$ berjarak $11 \mathrm{~nm}$, sementara untuk menuju YIA (WAHI) adalah $271^{\circ}$ berjarak $30,1 \mathrm{~nm}$.Terdapat dua disain panduan takeoff dari GDG ke JOG yaitu "Gading One Departure RW 28", dan "Gading Two Departure RW 10". Sedangkan panduan takeoff dari GDG ke YIA adalah "Gading Three Departure RW 28", dan "Gading Four Departure RW 10". Prosedur takeoff RW 28, setelah takeoff climb hingga 1.500 feet, pesawat melakukan turn right bergabung dengan flight rute DCT-01 menuju WAHH, atau pesawat melakukan turn left bergabung dengan flight rute DCT02 menuju WAHI. Sedangkan prosedur takeoff runway 10 adalah after climb hingga 1.500 feet melakukan trun right back track melintas VOR GDG selanjutnya bergabung dengan DCT 02 menuju ke YIA atau bergabung dengan DCT 01 menuju ke JOG.

\section{Daftar Pustaka}

[1] Syamsuar, Sayuti. Tahun 2015. Metoda Short Takeoff Landing (Studi Kasus Prestasi Terbang Takeoff-Landing Pesawat Udara Turbo Prop CN235)

[2] Setiawan, Dian M., Mahmudah, Noor., Putra, Edo Laksmana. Tahun 2019. Analisis Panjang Runway untuk Pendaratan dan Take-off Pesawat Airbus A330-200 dan A3 0300 .

[3] Susetyadi, Ari. Tahun 2018. Waktu Tunggu Takeoff dan Landing Pesawat Udara Pada Runway Bandar Udara Soekarno Hatta.

[4] Maulana, Agung A.Tahun 2018. Perancangan Procedure Turn Untuk Take Off Dan Landing Menggunakan Metode Procedure Turn Penerbangan Visual Flight Rules Pada Lapangan Terbang Gading.

[5] Department of Communications, Directorate General of Air Communications, Company Operations Manual, August 1999. 